\title{
EFICÁCIA DE SUBSTITUTOS DO PARAFORMALDEÍDO NA DESINFECÇÃO DOS NINHOS DE MATRIZES DE FRANGO DE CORTE
}

\author{
Lídia Szpakowski ${ }^{1}$, Bárbara Aline Lang Holz ${ }^{1}$, Luciana Bill Mikito Kottwitz ${ }^{1}$, Douglas \\ da Silva ${ }^{1}$
}

\author{
${ }^{1}$ Autonomo \\ Endereço para correspondência: Luciana Bill Mikito Kottwitz: lukottwitz@yahoo.com.br
}

\begin{abstract}
RESUMO: A avicultura é mundialmente o setor que apresenta maior velocidade de expansão entre os três principais setores que integram o complexo produtivo de carne. As práticas de manejo de aves têm sido constantemente aperfeiçoadas com adoção de novas técnicas. O presente trabalho teve como objetivo avaliar a possibilidade de substituição do paraformaldeído na desinfecção de ninhos de matrizes de frango de corte. Os tratamentos foram compostos por três diferentes produtos, o clorofenol, o paraformaldeído e aluminosilicato potencializado associado a ácidos orgânicos, distribuídos na forma de polvilhamento na maravalha dos ninhos. Foi efetuada a avaliação microbiológica após a desinfecção dos ninhos realizada na granja de produção de ovos (bactérias totais e bolores e leveduras) e análise de eclodibilidade e embriodiagnóstico no incubatório. Os resultados microbiológicos não apresentaram diferença significativa entre as médias dos tratamentos. Os índices de eclodibilidade encontrados foram de $85,71 \%$ para o paraformaldeído, $85,28 \%$ para o clorofenol e $83,99 \%$ para o aluminosilicato. Os resultados do embriodiagnóstico dos ovos não eclodidos indicaram maiores índices de mortalidade embrionária, precoce e intermediária, no período de 4 a 18 dias, em ovos desinfetados com paraformaldeído, evidenciando sua toxicidade. A maior eficácia na redução da contaminação microbiana e de eclodibilidade foram observados após tratamento com clorofenol.
\end{abstract}

Palavras-chave: aluminosilicato de cálcio; clorofenol; eclodibilidade, mortalidade embrionária; redução microbiana

\section{EFFECTIVENESS OF SUBSTITUTES PARAFORMALDEHYDE IN DISINFECTION OF NEST BROILER BREEDERS}

\begin{abstract}
This study aimed to evaluate the possibility of substitution of paraformaldehyde to disinfect nest broiler breeders. Three different products were used, chlorophenol, paraformaldehyde and aluminosilicate associated with organic acids, distributed in the form of spray from the nest. After disinfections procedures, eggs were evaluated for presence of total mesophyles, mould and yeast, embryo diagnosis and analysis of hatchability. Differences were not detected among treatments for microbiological results. Hatchability rates were: $85.71 \%$ for paraformaldehyde, $85.28 \%$ for chlorophenol and $83.99 \%$ for aluminosilicate. Eggs disinfected with paraformaldehyde had higher embryo mortality in the period from 4 to 18 days, suggesting toxicity. The best efficiency results in reduction of microbial contamination and hatchability were observed with the use of chlorophenol.
\end{abstract}

Key Words: calcium aluminosilicate; chlorophenol; embryo mortality; hatchability; microbial reduction 


\section{INTRODUÇÃO}

A avicultura é mundialmente o setor que apresenta maior velocidade de expansão entre os três principais setores que integram o complexo produtivo de carne (Medeiros, 2008). A integração entre a genética, nutrição, sanidade e o ambiente mostraram ser, ao longo do tempo, o caminho para a obtenção de uma produção altamente viável (Freitas; Costa, 2005).

As práticas de manejo de aves têm sido constantemente aperfeiçoadas com adoção de novas técnicas. É fato que os maiores cuidados com as matrizes e os ovos, irão refletir em melhores resultados nos pintos e, consequentemente, no produto final que vai à mesa do consumidor (Cony, 2007). Normalmente os ovos não apresentam micro-organismos na casca, na albumina e na gema. Entretanto, pode haver contaminação interna de ovos intactos decorrente de infecção do sistema reprodutor (Cony, 2007; Kottwitz, 2009). A contaminação externa ocorre através do contato com 0 ambiente após a postura ou, no momento da postura, durante o trânsito pela cloaca, devido o contato da casca com as fezes da ave (Alegro-Aragon et al. 2005; Téo; Oliveira, 2005).

Entre as práticas relacionadas ao manejo e à sanidade de matrizes de corte, destaca-se a desinfecção dos ovos que, necessariamente, deve ser feita corretamente e com os desinfetantes permitidos e adequados. A ineficácia deste processo certamente acarretará em perdas consideráveis na eclodibilidade, assim como aumento da mortalidade de pintos no campo, redução dos índices de eficiência produtiva (IEP) e, consequentemente, aumento nos custos de produção (Cony, 2007).

O ninho é o primeiro contato que o ovo possui com o ambiente externo (Freitas, 2007) assim, as condições de higiene são muito importantes nesse momento. As técnicas de desinfecção de ovos e manejo das instalações são amplamente aplicadas para 0 impedimento da proliferação de microorganismos patogênicos.

Os métodos de desinfecção de ovos, comumente utilizados na indústria, são a fumigação (volatilização de um desinfetante), a pulverização e a imersão (Cony et al., 2008). Diversos são os produtos disponíveis para a realização desses procedimentos, entre eles o formaldeído, amônia quaternária associada ao glutaraldeído, digluconato de clorexidina e fenol sintético (Cony, 2007).

Atualmente, no processo de desinfecção das bocas de ninhos de matrizes de corte, utiliza-se paraformaldeído, pelo método de polvilhamento dos ninhos. A legislação vigente, a Resolução RDC n 91/ 2008 da Agência Nacional de Vigilância Sanitária - ANVISA (Brasil, 2008), próibe o uso isolado de produtos que contenham paraformaldeído ou formaldeído, para desinfecção e esterilização, devido a sua reconhecida carcinogenicidade e atual classificação toxicológica pela IARC (International Agency for Research on Câncer).

O formaldeído é um aldeído altamente reativo e com poder germicida comprovado, possui ainda poder esporicida, agindo por um tempo superior a 18 horas. No entanto, apresenta desvantagens como: redução da eficácia em presença de matéria orgânica; é corrosivo para metais; deixa resíduos tóxicos nos equipamentos; é considerado como carcinogênico pelo National Institute of Occupational Safety Health (NIOSH); e quando utilizado de maneira inadequada pode causar riscos à eclodibilidade, conversão alimentar e outros danos a saúde das aves (Cony, 2007).

Considerando que a fumigação com paraformaldeído é um método 
eficaz de desinfecção dos ovos por sua ação bactericida efetiva contra microorganismos patogênicos, a sua substituição deve ser realizada por métodos igualmente eficazes na redução da contaminação microbiana e seguros sob 0 ponto de vista toxicológico.

Técnicas alternativas estão sendo testadas, entre elas citam-se 0 clorofenol, um composto fenólico halogenado que apresenta ação antibacteriana e melhor atuação frente à matéria orgânica (O`Connor; Rubino, 1991), e o alumínio silicato de cálcio potencializado, um produto de origem orgânica não volátil, atóxico para o homem e para as aves, além de não apresentar características corrosivas.

O presente trabalho teve como objetivo avaliar a substituição do paraformaldeído por produtos alternativos, na desinfecção de ninhos de matrizes de frango de corte verificando a eficácia de redução e/ou eliminação dos micro-organismos presentes nos ovos de incubação e os possíveis efeitos tóxicos associados ao produto.

\section{MATERIAL E MÉTODOS}

O experimento foi conduzido em uma integração avícola localizada na região Oeste do estado do Paraná, consistindo na avaliação microbiológica da desinfecção dos ninhos realizada na granja de produção de ovos e análise de eclodibilidade e embriodiagnóstico no incubatório.

A pesquisa foi realizada em três galpões $(A, B, C)$ de matrizes de corte com 51 semanas de idade da linhagem Ross 308. Os galpões apresentam $12 \mathrm{x}$ 154 metros e a temperatura interna dos mesmos são monitorados e controlados a fim de manter um ambiente dentro da zona de conforto das aves. O controle de temperatura, ventilação e umidade é programado por meio de um painel de comando do galpão. Para o controle de temperatura do galpão, são utilizados os seguintes parâmetros: $1^{\underline{a}}$ semana de 30 $32{ }^{\circ} \mathrm{C}, 2^{\mathrm{a}}$ semana de $28-30{ }^{\circ} \mathrm{C}, 3^{\mathrm{a}}$ semana de $26-28^{\circ} \mathrm{C}$ e da $4^{\mathrm{a}}$ semana em diante de 24-26 ${ }^{\circ} \mathrm{C}$.

Cada galpão alojava, aproximadamente, 9.350 aves, com 2.077 bocas de ninhos, representando um total de 6.231 bocas de ninhos. Realizou-se a amostragem de 2,5\% destas bocas, sendo 50 bocas de ninhos por galpão, totalizando 150 bocas de ninhos.

Os tratamentos foram compostos por três diferentes produtos, sendo os princípios ativos desinfetantes: cloro ativo associado com fenóis, paraformaldeído ou aluminosilicato potencializado associado a ácidos orgânicos (propiônico, acético, sórbico e fórmico).

No galpão $A$ foi realizado uma aplicação de 10 gramas de cloro ativo associado com fenóis (5\% de cloro ativo e $0,5 \%$ de fenóis). No galpão B o método utilizado foi o tradicional com aplicação de 10 gramas de paraformaldeido ( $91,92 \%$ de formol). No galpão C, foram aplicadas 10 gramas de aluminosilicato potencializado associado a ácidos orgânicos $(75 \%$ de aluminosilicato e $25 \%$ de ácidos propiônico, acético, sórbico e fórmico), segundo a recomendação dos fabricantes. $O$ experimento teve duração de 15 dias a partir da data inicial de inclusão dos produtos. No primeiro dia, os desinfetantes foram distribuídos na forma de polvilhamento manual na maravalha das bocas de ninho, sendo que a reposição da maravalha nos ninhos foi realizada sobre os produtos. A maravalha utilizada nos ninhos é proveniente de madeira de eucalipto e é submetida à fumigação com paraformaldeído antes do uso.

A partir do dia da inclusão dos produtos químicos, iniciou-se a colheita de material para exames 
microbiológicos. Um total de trezentos e sessenta ovos foram coletados para análise microbiológica, sendo 120 de cada tratamento.

De cada galpão foram coletados, na parte superior dos ninhos, para evitar uma possível contaminação da maravalha da cama com os ninhos nas partes inferiores dos mesmos, 40 ovos nos três dias de avaliação dos tratamentos (1으. $8^{\circ}$ e $15^{\circ}$ dia), que foram divididos em quatro sub-amostras compostas por 10 ovos cada e de onde foram recolhidos os suabes, transportados em solução salina $0,9 \%$ e encaminhados para análises microbiológicas de contagem de bolores e leveduras e de bactérias totais, conforme os métodos analíticos descritos na Instrução Normativa $n^{\circ}$ 62/2003 do Ministério da Agricultura, Pecuária e Abastecimento - MAPA (Brasil, 2003).

Ainda, durante 0 experimento, foram realizadas coletas diárias de ovos destinados à incubação, os quais foram identificados na saída das granjas para o incubatório. Cada coleta consistiu de 480 ovos por tratamento/dia, totalizando 5.760 ovos/tratamento ao final do estudo.

Após a identificação das caixas, os ovos foram fumigados com paraformol na saída das granjas.

No incubatório os ovos foram classificados e armazenados na sala de estoque, onde permaneceram por três dias, em temperatura controlada de $20^{\circ} \mathrm{C}$ para posterior incubação. Após, foram alojados em incubadora a uma temperatura de $37,4^{\circ} \mathrm{C}$ por 19 dias, em seguida foram transferidos para 0 nascedouro, onde permaneceram por dois dias, até o seu nascimento.

Ao final da eclosão, após a remoção dos pintos, foi realizado o teste de embriodiagnóstico para determinar as causas do não nascimento, ou seja, se houve infertilidade ou mortalidade embrionária. A técnica consiste na avaliação interna dos ovos para a determinação das causas da não eclosão através da quebra de ovos não eclodidos, para avaliar o percentual de eclodibilidade sobre os ovos férteis, mortalidade embrionária de um a três, quatro a sete, oito a 14,15 a 18 e 19 a 21 dias de incubação, ovos contaminados e índices de contaminação visual.

Os dados obtidos foram tabulados em planilha do programa Microsoft Excel versão 2007. As médias dos tratamentos foram submetidas à análise de variância, comparadas pelo teste de Tukey, utilizando software SAEG, da Universidade de Viçosa, com nível de significância de $\mathrm{P} \leq 0,05$

\section{RESULTADOS E DISCUSSÃO}

Os resultados médios para contagem bacteriana total de cada um dos tratamentos são apresentados na Tabela 1. O tratamento B apresentou menores níveis de bactérias totais, que pode ser justificada por uma maior efetividade do paraformaldeído como bactericida, descrita por outros pesquisadores (O'connor; Rubino, 1991; Scott; Swetan, 1993; Donassolo; Costa, 2004). Porém, considerando este parâmetro de avaliação, não houve diferença significativa $(P \leq 0,05) \quad$ em relação ao tratamento $A$. 
Tabela 1 - Análises microbiológicas das cascas de ovos provenientes de ninhos de matrizes de corte submetidos à desinfecção com diferentes princípios ativos, na região Oeste do Paraná 2009.

\begin{tabular}{|c|c|c|}
\hline \multirow{4}{*}{ Tratamentos } & \multirow{4}{*}{$\begin{array}{l}\text { Níveis de } \\
\text { UFC/cm² } \\
\text { Bactérias } \\
\text { Totais }\end{array}$} & \multirow[t]{2}{*}{ contaminação } \\
\hline & & \\
\hline & & Bolores \\
\hline & & Leveduras \\
\hline Clorofenol (A) & $\begin{array}{l}3,2 \times 10^{4} \pm \\
2,0 \times 10^{4 a}\end{array}$ & $\begin{array}{l}1,2 \times 10^{2} \pm \\
1,9 \times 10^{2 a}\end{array}$ \\
\hline $\begin{array}{l}\text { Paraformaldeído } \\
\text { (B) }\end{array}$ & $\begin{array}{l}3,0 \times 10^{4} \pm \\
1,5 \times 10^{4} \mathrm{a}\end{array}$ & $\begin{array}{l}1,9 \times 10^{2} \pm \\
2,3 \times 10^{2 a}\end{array}$ \\
\hline $\begin{array}{l}\text { Aluminosilicato } \\
\text { (C) }\end{array}$ & $\begin{array}{l}4,9 \times 10^{4} \pm \\
3,3 \times 10^{4} a\end{array}$ & $\begin{array}{l}1,7 \times 10^{2} \pm \\
2,0 \times 10^{2} \mathrm{a}\end{array}$ \\
\hline Média & $3,7 \times 10^{4}$ & $1,6 \times 10^{2}$ \\
\hline$p$-valor & 0,365 & 0,676 \\
\hline CV\% & $9,34^{*}$ & $44,55^{*}$ \\
\hline
\end{tabular}

${ }^{\star}$ Os dados foram submetidos a transformação logarítmica.

**Médias seguidas de letras iguais na mesma coluna não diferem estatisticamente entre si pelo teste de Tukey a 5\% de significância.

Neste experimento não houve diferença significativa $(P \leq 0,05)$ entre as médias dos tratamentos (Tabela 1). Resultados diferentes foram relatados por Scott e Swetnam (1993) e Cony (2007) que, ao analisarem diversos desinfetantes quanto à sua capacidade de redução microbiana na casca de ovos, concluíram que os desinfetantes a base de compostos fenólicos, apesar de reduzirem a população microbiana, não apresentaram a mesma eficácia quando comparados ao formol.

No presente estudo, o uso de aluminosilicato (tratamento $\mathrm{C}$ ) registrou contagem bacteriana superior aos outros tratamentos (Tabela 1). Apesar das vantagens quanto ao uso de ácidos, que são produtos orgânicos, relata-se uma baixa atividade dos mesmos para redução da contaminação microbiana. Os ácidos orgânicos associados ao aluminosilicato, promovem a acidificação temporária inibindo bactérias patogênicas. $O$ mecanismo antibacteriano dos ácidos orgânicos não é completamente compreendido e a atividade bactericida pode variar, dependendo das características físicoquímicas do meio (Medeiros, 2008).

Analisando todo o período do estudo, houve o aumento significativo da carga bacteriana após o 9ํ dia em todos os tratamentos. Este fato pode ser explicado pela diminuição da eficácia dos produtos em função da redução da concentração dos princípios ativos ao longo do tratamento e pela possível contaminação dos ninhos pela circulação das aves no interior dos galpões.

O paraformaldeído é um polímero que, em seu processo de decomposição, origina o formaldeído, que não possui efeito residual (Favero; Blond, 1991), desta forma, tem redução de efeito ao longo do tempo. O fenol atua como redutor de $\mathrm{pH}$, facilitando a liberação de cloro como agente desinfetante oxidante, sendo que dessa forma a quantidade de cloro livre é reduzida ao longo do tratamento (O'Connor; Rubino, 1991). Segundo Fireman (2007), o aluminosilicato é usado com adsorvente para a remoção de micotoxinas de grãos e de rações, o processo de adsorção é a adesão de moléculas de um fluido a uma superfície sólida, como o produto tem a finalidade de reduzir a umidade do meio, com o passar do tempo a superfície adsorvente satura-se diminuindo a eficiência da redução da umidade o que pode ser comprovado através dos resultados onde observa-se o aumento da contaminação bacteriana.

Scott e Swetnam compararam formaldeído a outros vinte e dois desinfetantes em relação à redução microbiana na casca de ovos incubáveis, sendo que apenas quatro não alcançaram a redução na contagem microbiológica diferindo estatisticamente dos demais, não estando entre eles o formaldeído.

Sacco et al. (1989) compararam fumigação com formol e desinfecção com amônia quaternária a fim de 
verificar a redução bacteriana na casca e na gema de ovos pós-desinfecção e não encontraram diferenças entre os tratamentos.

Ovos desinfetados com aluminosilicato e clorofenol, apresentaram níveis de bolores e leveduras inferiores quando comparados ao uso do paraformaldeído (Tabela 1), no entanto essa diferença não é estatisticamente significativa.

A análise de bolores e leveduras demonstrou que todos os tratamentos apresentaram alta contagem fúngica no início do tratamento (dados não apresentados), podendo estar relacionada com a contaminação dos ninhos.

Alguns fatores interferem neste aspecto, entre eles estão associados a qualidade da maravalha utilizada, a temperatura, a umidade que é influenciada pelo posicionamento dos ninhos no interior do galpão e pela redução da concentração dos princípios ativos (Paganini, 2004).

O'Connor e Rubino (1991) afirmam que os compostos fenólicos atuam inativando enzimas essenciais para a manutenção de microorganismos em baixas concentrações. Enquanto que o formaldeído, produto originado da degradação do paraformaldeído, tem sua ação afetada na presença de matéria orgânica, fato que está associado à reposição da maravalha nos ninhos (Demasi, 1991).

A maravalha utilizada no revestimento dos ninhos sofreu tratamento prévio para descontaminação, sendo que usualmente a mesma é adquirida através de fornecedores selecionados e passa por processo de fumigação no armazenamento. Assim, os resultados observados reforçam a importância de cuidados relativos ao armazenamento e desinfecção dos materiais utilizados como cama de aviários.
Para evitar problemas sanitários relacionados à contaminação fúngica, a partir do material a ser utilizado como cama para aves, é indispensável tratá-lo com produtos com comprovada ação antifúngica. Com isso, assegura-se que a cama utilizada nos aviários possa estar isenta ou possuir baixa contaminação por fungos (Santos et al. 2000).

Os resultados da avaliação de eclodibilidade e embriodiagnóstico dos ovos não eclodidos, provenientes de ninhos submetidos à desinfecção por pulverização com diferentes princípios ativos, realizados no incubatório, estão apresentados na Tabela 2.

Tabela 2 - Eclodibilidade e embriodiagnóstico dos ovos não eclodidos, provenientes de ninhos submetidos à desinfecção por pulverização, na região Oeste do Paraná - 2009.

\begin{tabular}{lccc}
\hline \hline Tratamentos & Cbrónol & Paraformaldeido & Aluminosilicato \\
\hline Wortalidade 1-3 dias (\%) & 1,25 & 1,35 & 1,13 \\
Wortalidade 4-7 dias (\%) & 0,29 & 0,45 & 0,51 \\
Wortalidade 8-14 dias (\%) & 1,22 & 1,44 & 1,30 \\
Wortalidade 15-18 dias (\%) & 0,47 & 0,85 & 0,47 \\
Wortalidade 19-21 dias (\%) & 0,56 & 0,47 & 0,61 \\
Jios năo fertlizados (\%) & 8,92 & 7,36 & 8,32 \\
Zontaminados (\%) & 0,21 & 0,00 & 0,21 \\
Jutras causas' $(\%)$ & 0,53 & 0,81 & 0,70 \\
Eclodibilidade $(\%)$ & 85,28 & 85,71 & 83,99 \\
\end{tabular}

Outras causas ${ }^{1:}$ refugo, podre, trincado, mal posicionado, bicado, nanismo, anormal e hemorrágico.

Ainda que o índice de ovos não fertilizados observados em ovos desinfetados com clorofenol tenha sido superior ao dos demais princípios ativos (Tabela 2), os resultados de eclodibilidade para os três tratamentos foram semelhantes, registrando índices de $85,71 \%$ para o paraformaldeído, $85,28 \%$ para o clorofonenol, e $83,99 \%$ para o aluminosilicato. Observou-se um índice médio de eclosão de $82,56 \%$ para o restante dos ovos eclodidos no mesmo período de tratamento, esta diferença pode estar influenciada por manejos diferentes destes ovos com 
relação aos ovos coletados para 0 estudo.

Estes resultados estão de acordo com o potencial de eclosão preconizado pelas empresas que comercializam matrizes pesadas da linhagem ROSS, descrito nos manuais de produção, para a idade de 51 semanas, que é de $84,00 \%$ (Aviagen, 2008).

Whistler e Sheldon

conduziram um estudo em que foram comparadas as fumigações com formaldeído e com ozônio. Avaliando a eclodibilidade dos ovos férteis, os autores detectaram diferença significativa, sendo o grupo tratado com formaldeído superior, com maior eclodibilidade de ovos férteis $(89,4 \%)$, se comparado ao grupo tratado com ozônio (50\%), ou seja, não constataram perdas de produtividade relacionadas ao uso de formaldeído. Índices de eclosão superiores ao encontrado neste estudo foram observados por Cony et al. (2008) que, ao avaliarem a eficiência de diferentes princípios ativos na desinfecção de ovos provenientes de matrizes pesadas da linhagem ISA Vedette com 42 semanas de idade, verificaram percentuais médios de eclodibilidade de $94 \%$, sendo que ovos pulverizados com fenol e formaldeído registraram $93,9 \%$ e $93,4 \%$, respectivamente.

Os resultados do embriodiagnóstico dos ovos não eclodidos indicam os menores índices de mortalidade com o uso de clorofenol e os maiores índices de mortalidade embrionária precoce e intermediária, entre oito e 18 dias, em ovos desinfetados com paraformaldeído (Tabela 2).

Índices de mortalidade precoce e intermediária frequentemente estão relacionados a técnicas de manejo, incluindo irregularidades na desinfecção dos ovos nas granjas. A mortalidade final (19 a 21 dias) geralmente está associada a causas nutricionais ou à ambiência nos nascedouros devido ao desenvolvimento pulmonar e início da respiração.

Diversos trabalhos têm sido realizados com a finalidade de encontrar um substituto com a mesma eficácia do formaldeído para desinfecção de ovos incubáveis, devido às restrições de uso deste produto reconhecidamente tóxico.

$\mathrm{Da}$ mesma forma que a presente pesquisa, outros estudos evidenciaram a toxicidade do formaldeído. Sheldon e Brake (1991) avaliaram eclodibilidade, mortalidade de um a sete e de oito a 20 dias em ovos desinfetados por meio de fumigação com formaldeído, comparados a um grupo pulverizado com peróxido de hidrogênio e outro grupo com água estéril. Estes autores detectaram diferenças na mortalidade de oito a 20 dias, constatando maior mortalidade no grupo tratado com formaldeído.

O formaldeído é um carcinógeno conhecido, e também causa danos ao sistema mucociliar do trato respiratório em embriões de pintinhos (Walker; Sander, 2004).

Gerrits (1991), ao avaliar a traquéia de aves provenientes de ovos fumigados com formaldeído, verificou danos epiteliais severos, redução no número de células ciliares, inflamações, hemorragias, proliferações celulares e redução das células mucosas.

Sander e Wilson (1995) relataram que a exposição de embriões de galinha ao gás formaldeído, durante os três últimos dias de incubação, causou alterações funcionais e morfológicas na traquéia de pintos até os cinco dias de idade. As traquéias destes pintos apresentaram mobilidade ciliar reduzida e, ao serem analisadas em microscopia de luz, observaram-se poucos cílios, vesículas na superfície ciliar, muco em excesso e desprendimento do epitélio traqueal.

Entretanto, ao avaliar ovos fumigados com formaldeído e ovos 
lavados com amônia quaternária, Sacco et al. (1989) verificaram melhores resultados de nascimento e viabilidade embrionária no $7^{\circ}$ dia de incubação para - grupo tratado com formaldeído, mesmo sem detecção de diferença estatística.

Segundo Scott e Swetnam (1993), a contaminação dos ovos incubáveis por micro-organismos resulta no aumento do número de ovos podres na incubadora, aumento de infecções sistêmicas e, consequentemente, aves de pouca qualidade e redução do desempenho zootécnico e viabilidade das aves.

É amplamente aceito que a contaminação bacteriana é um fator que contribui consideravelmente para a redução de eclosão em incubatórios comerciais e são muito válidos os esforços despendidos na tentativa de minimizar tais infecções (Bruce; Drysdale, 1991).

Neste estudo, ovos provenientes de ninhos desinfetados com paraformaldeído registraram ausência de ovos contaminados (Tabela 2), comparado aos outros tratamentos. Este resultado reforça 0 potencial de desinfecção deste produto.

Porém, apesar do seu reconhecido poder desinfetante o formaldeído possui diversos aspectos negativos, especialmente no que diz respeito à saúde das pessoas sujeitas à exposição diária (Cony, 2007). Portanto, é recomendada a substituição deste produto químico devido ao seu alto poder toxigênico mesmo possuindo indiscutível efetividade em relação à sanitização dos ovos (Scott; Swetnam, 1993).

\section{CONCLUSÃO}

Desinfetantes apresentam um papel importante na descontaminação dos ovos férteis e nos resultados de produção. Neste trabalho a melhor eficiência na redução da contaminação microbiana e os melhores resultados de eclodibilidade foram observados com a utilização do clorofenol e do paraformaldeído. Entretanto, a mortalidade embrionária precoce e intermediária observada em ovos desinfetados com paraformaldeído, reforçam a toxicidade do mesmo e reforçam a necessidade de estudos mais amplos e detalhados que viabilizem a recomendação de uso de outros produtos para desinfecção, como o clorofenol.

\section{REFERÊNCIAS}

ALEGRO-ARAGON, L. C. SOUZA, K. L. O. et al. 2005. Avaliação da qualidade microbiológica de ovo integral pasteurizado produzido com e sem etapa de lavagem no processamento. Ciência e Tecnologia de Alimentos, v. 25, n. 03, Campinas, 2005. Disponível em: < http://www.scielo.br>. Acesso em: 10 dez. 2009.

BRASIL. Ministério da Agricultura, Pecuária e Abastecimento. Secretaria de Defesa Agropecuária. Métodos Analíticos Oficiais para Análises Microbiológicas para Controle de Produtos de Origem Animal e Água. Instrução Normativa no 62, de 26/08/2003. Diário Oficial da Republica Federativa do Brasil, Brasília, seção I, p.14-51, 18 set. 2003.

BRASIL. Resolução RDC № 91, de 28 de novembro de 2008. Proíbe o uso isolado de produtos que contenham paraformaldeído ou formaldeído, para desinfecção e esterilização, regulamenta o uso de produtos que contenham tais substâncias em equipamentos de esterilização e dá outras providências. Agência Nacional da Vigilância Sanitária. Diário Oficial da República Federativa do Brasil, Brasília, 01 de dezembro de 2008.

BRUCE, J.; DRYSDALE, E. M. Egg hygiene: Routes of infection. In: TULLET, S.G. Avian Incubation. London: Butterworth-Heinemann, 1991. p. 257-267. Trabalho apresentado $n^{\circ} 22$. Poultry Science Symposium. 
CONY H.C. Métodos de desinfecção e princípios ativos e desinfetantes e a contaminação, mortalidade embrionária e eclodibilidade de ovos e embriões de aves. 2007. Porto Alegre, 101 f. Dissertação (Mestre em Zootecnia Área de produção animal) - Universidade Federal do Rio Grande do Sul.

CONY, H. C. et al. Técnicas de pulverização e imersão com distintos desinfetantes sobre ovos incubáveis. Ciência Rural, v. 38 , n.5, p. 14071412, 2008

DEMASI, M. Anti-sépticos, desinfetantes, esterilizantes. In: VALE, L.B.S. et al. Farmacologia integrada, fundamentos farmacológicos da terapêutica. São Paulo: Ateneu, 1991. V.2, p.576-606.

DONASSOLO, E.; COSTA, G. C. N. Ação do fenol sintético e do aldeído fórmico na proteção de embriões de Gallus gallus para fins comerciais. 2004. Cascavel, 48f. (Monografia) Universidade Paranaense. Trabalho de Conclusão do Curso de Ciências Biológicas.

FAVERO, M.S.; BLOND, W.W. Chemical disinfection of medical and surgical materials. In: BLOCK, S.S. Disinfection, Sterilization and Preservation. 4th ed. Philadelphia: Lea \& Febiger, 1991. p. 617-641.

FIREMAN, Alba. Micotoxinas - A Importância do Gerenciamento, dos Métodos Diagnósticos Corretos e da Escolha do Produto Certo para Evitar seus Efeitos Deletérios sobre a Produção Animal, 2007. Disponível em: <http://www.avisite.com.br>. Acesso em: 29 set. 2010.

FREITAS, A. G.; COSTA, C. A. Pontos críticos no manejo de matrizes pesadas. In: MACARI, M.; MENDES, A. A. Manejo de matrizes de corte. 2. ed. Campinas: FACTA, 2005. Cap. 8, p. 173-184.

FREITAS A. G. Efeito da fumigação de nascedouros com formaldeído sobre o trato respiratório e desempenho de frangos de corte. 2007. Uberlândia, 59f. Dissertação (Mestre em Ciências Veterinárias Produção Animal) Universidade Federal de Uberlândia.
GERRITS, A.R. Formalin fumigation during pipping and hatching. In: TULLET, S.G. Avian Incubation. London: Butterworth-Heinemann, 1991. p. 293-295. Trabalho apresentado $n^{\circ} 22$. Poultry Science Symposium.

GODOY, J. C. Tendência do Mercado de Aves. Avicultura Industrial, Porto Feliz, n. 1085, 2001. Disponível <http://www.aviculturaindustrial.com.br > Acesso em: 29 set. 2010.

KOTTWITZ, L. B.M. Salmonella spp.: Avaliação epidemiológica de surtos notificados no Paraná e caracterização de isolados epidêmicos e de origem avícola. Londrina, 2009. 124p. Tese (Doutorado em Ciência de Alimentos) Universidade Estadual de Londrina - PR.

AVIAGEN. MANUAL DE MANEJO DE MATRIZES ROSS:Objetivos de Desempenho e Especificações Nutricionais Ross 308. Aviagen do Brasil Ltda, Campinas, 2008.

MEDEIROS, P. T. Produção avícola: Subsídios na busca de sistemas de alimentação saudáveis, econômicos e de menor impacto ambiental. 2008. Florianópolis, 93f. Dissertação (Mestre em Agroecossistemas) - Universidade Federal de Santa Catarina.

O'CONNOR, D.O.; RUBINO, J.R. Phenolic compounds. In: BLOCK, S.S. Disinfection, Sterilization and Preservation. 4. ed. Philadelphia: Lea \& Febiger, 1991. p. 204-224.

PAGANINI, FJ. Manejo da Cama. In: Mendes AA, Naas IA, Macari M. (Eds) Produção de frangos de corte. Campinas, FACTA. p.107-116. 2004.

SACCO, R. E. et. al. Effect of hatching egg sanitizers on embryonic survival and hatchability of turkey eggs from different lines and on eggs shell bacterial populations. Poultry Science, Savoy, I.L, v. 68, p. 1179-1184, 1989.

SANDER, J. E.; WILSON, J. L.; ROWLAND, G. N.; MIDDENDORFF P. J. Formaldheyde Vaporization in the hatcher and effect on tracheal epithelium of chick.

Avian Diseases, Ithaca, v. 39, p. 152-157, 1995. 
SANTOS, B.M. et. al. Avaliação da atividade antifúngica de três compostos recomendados para tratamento de cama de aviário. 2000. Viçosa. Universidade Federal de Viçosa.

SCOTT, T.A.; SWETNAM, C. Screening sanitizing agents and methods of application for hatching eggs. II. Effectiveness against microorganisms on the egg shell. Journal Applied Poultry Research, Athens, GA, v.2, p. 7-11, 1993.

SHELDON, B.W.; BRAKE, J. Hydrogen peroxide as an alternative hatching egg disinfectant. Poultry Science, Savoy, IL, v.70, p.1092-1098, 1991.

TÉO, C.R.P.A.; OLIVEIRA, T.C.R.M. Salmonella spp.: The eggs as vehicle of transmission and the implications of resistance for public health. Semina: Ciências Agrárias, v.26, n.2, p.195210, 2005.

UNIVERSIDADE FEDERAL DE VIÇOSA-UFV. SAEG - Sistema para análises estatísticas. versão 9.0. Viçosa, MG: Universidade Federal de Viçosa, 2001. (CD-ROM).

WALKER, S. E.; SANDER, J. E. Effect of biosentry 904 and ethylenediaminetetraacetic acid-tris disinfecting during incubation of chicken eggs on microbial levels and productivity of poultry. Avian Diseases, Ithaca, v. 48, p. 238243, 2004.

WHISTLER, P.E.; SHELDON, B.W. Bactericidal activity, eggshell conductance, and hatchability effects of ozone versus formaldehyde disinfection. Poultry Science, Savoy, IL, v.68, p.1074-1077, 1989. 